\title{
SPK Rekomendasi Pemilihan Kandidat Pejabat Struktural Menggunakan Metode Profile Matching (Studi Kasus: Pemerintah Kota Tarakan)
}

\author{
Ria Astriratma*1, Retantyo Wardoyo ${ }^{2,}$ Aina Musdholifah ${ }^{3}$ \\ ${ }^{1}$ Program studi S2 Ilmu Komputer FMIPA UGM, Yogyakarta \\ 2,3 Jurusan Ilmu Komputer dan Elektronika, FMIPA UGM, Yogyakarta \\ e-mail: *11 riailkom@gmail.com, ${ }^{2}$ rw@ugm.ac.id, ${ }^{3}$ aina m@ugm.ac.id
}

\begin{abstract}
Abstrak
Melalui Undang-Undang Aparatur Sipil Negara, Pemerintah melakukan upaya mengurangi nepotisme dengan menciptakan sistem kompetisi yang terbuka di antara PNS dalam proses pengisian jabatan. Badan Kepegawaian Daerah (BKD) Tarakan telah memiliki basis data pegawai dan sistem pendukung keputusan yang dapat menggabungkan basis data yang tersedia dengan model penilaian untuk mendapatkan profil calon yang cocok dengan profil jabatan yang lowong diperlukan untuk menunjang kinerja yang lebih objektif.

Penerapan metode profile matching dalam sistem pengambilan keputusan ini diharapkan dapat membantu proses rekomendasi pemilihan kandidat pejabat struktural di lingkungan Pemerintahan Kota Tarakan sesuai dengan kemampuan bidang yang dibutuhkan dalam suatu jabatan.

Dari hasil penelitian diperoleh kesimpulan bahwa perubahan nilai profil kandidat, dan jumlah subkriteria yang digunakan untuk kriteria jabatan, dapat mempengaruhi kedekatan kandidat dengan jabatan yang tersedia dan penggunaan metode profile matching untuk kasus yang mengganggap bahwa nilai tertinggi adalah nilai terbaik mengharuskan nilai ideal yang digunakan merupakan nilai maksimum agar tidak terjadi ekspektasi yang melebihi nilai ideal.
\end{abstract}

Kata kunci-Sistem Pengambil Keputusan, Profile Matching, Kota Tarakan

\begin{abstract}
Through the State Civil Apparatus Law, the Government attempt to reduce nepotism by creating an open competition system among civil servants in the process of filling positions. Regional Civil Service Agency (BKD) Tarakan already has personnel database and decision support system that can combine the existing database with the scoring model to get the candicate profile who fit with vacant positions is needed to support more objective performance.

The Application of profile matching method in this decision support system is expected to help the candidate selection process on structural officer in the Government of Tarakan comply with the ability of a required field in a position.

From the research we concluded that the change in the value of the candicate profile, and the number of subcriteria that used to categorize the positions can affect the closeness of candidates with vacant position and the use of profile matching method for case that the highest value is the best value requires that the ideal value used is the value the maximum in order to avoid exceeding the expectations of ideal.
\end{abstract}

Keywords-Decision Support System, Profile Matching, Government of Tarakan 


\section{PENDAHULUAN}

P enempatan PNS dalam jabatan struktural dilakukan berdasarkan pertimbangan objektif antara kompetensi, kualifikasi, dan persyaratan yang dibutuhkan oleh jabatan tanpa membedakan jenis kelamin, suku, agama, ras, dan golongan untuk menghasilkan PNS yang profesional [1]. Promosi dan mutasi adalah aspek yang berdampak terhadap prestasi kerja yang bersangkutan secara simultan dan berpengaruh signifikan positif terhadap pengembangan karir pegawai dalam rangka menambah pengalaman masing-masing aparatur untuk meningkatkan kualitas SDM aparatur dalam kerangka kinerja dan tanggung jawabnya [2].

Baperjakat belum mampu memberikan argumentasi berupa data atau informasi yang dapat memberikan pertimbangan kepada Pejabat Pembina Kepegawaian dalam pengangkatan, pemindahan, pemberhentian dari jabatan struktural. Hal tersebut disebabkan data/ informasi pegawai yang masih belum baik dan belum adanya perangkat pemilihan kandidat eselon IIIb ke bawah yang mampu memberikan penilaian objektif sebagaimana diatur oleh Permendagri Nomor 5 tahun 2005. Banyak peraturan perundang-undangan yang selama ini mengatur manajemen PNS yang pelaksanaannya perlu disesuaikan dengan tuntutan dan perkembangan zaman. Baperjakat dalam memberikan pertimbangan dan menentukan pengembangan karir harus mengedepankan prinsip profesionalisme, dan perlu adanya "Fit and Proper Test" untuk menemukan kecocokan antara jabatan yang akan diisi dengan kemampuan seorang calon sehingga kesenjangan kompetensi dapat diatasi [3].

Badan Kepegawaian Daerah (BKD) Tarakan telah membangun basis data pegawai guna menunjang pengambilan keputusan Baperjakat. Namun, basis data tersebut baru mampu memberikan pilihan berdasarkan daftar urut kepangkatan. Data tersebut sebenarnya dapat mendukung penerapan model penilaian yang terdapat pada Permendagri Nomor 5 Tahun 2005 dengan dibangun sebuah sistem pendukung keputusan untuk memberikan penilaian objektif dalam pemilihan kandidat pejabat struktural. Untuk menunjang kinerja Baperjakat yang lebih objektif, diperlukan sistem pendukung keputusan yang dapat menggabungkan basis data yang tersedia dengan model penilaian untuk mendapatkan profil calon yang cocok dengan profil jabatan yang lowong. Sehingga dalam hal mengangkat seseorang dalam jabatan bukan hanya tingkat minimal yang harus dipenuhi atau dilewati melainkan terdapat tingkat variabel prediktor yang ideal yang harus dimiliki oleh kandidat [4].

Sistem Pendukung Keputusan merupakan sekumpulan prosedur berbasis model untuk pemrosesan data dan penilaian guna membantu para pengambil keputusan untuk mengambil keputusan dalam situasi yang semiterstruktural dan situasi yang tidak terstruktur secara cepat dan mudah [5]. Penelitian mengenai model pengambilan keputusan dalam berbagai permasalahan cukup banyak dilakukan, di antaranya Handojo yakni pengambilan keputusan terhadap proses kenaikan jabatan dan perencanaan karir dengan menggunakan profile matching dan analisis gap [6]. Algoritma Profile matching yang dijelaskan dalam penelitian Lu yakni memberikan pilihan sport channel yang sesuai dengan keinginan user [7]. Pada penelitian Biesalski juga ditunjukkan bahwa sebuah rencana kesuksesan untuk menyesuaikan kompetensi pada pekerjaan tertentu ialah dengan membandingkan skill-profile dari sebuah posisi yang tersedia dengan kompetensi karyawan yang dimiliki untuk menemukan kandidat yang paling sesuai dengan kebutuhan [8]. Iqbal melakukan penelitian yang bertujuan membangun sistem pendukung keputusan penentuan penempatan bidan PTT [9].

Berdasarkan uraian tersebut diatas dapat disimpulkan bahwa permasalahan Baperjakat di BKD Tarakan dapat disolusikan dengan pembuatan sistem pendukung keputusan. Penerapan metode profile matching dalam membangun sistem pengambilan keputusan ini diharapkan dapat membantu proses rekomendasi pemilihan kandidat pejabat struktural di lingkungan Pemerintahan Kota Tarakan agar lebih objektif. Sistem pendukung keputusan yang dibangun bertujuan untuk memperoleh urutan rekomendasi pegawai sesuai dengan profil jabatan lowong.

IJCCS Vol. 11, No. 1, January 2017 : $77-88$ 


\section{METODE PENELITIAN}

\subsection{Deskripsi Sistem}

Sistem pendukung keputusan pada dasarnya merupakan sekumpulan prosedur berbasis model untuk pemrosesan data menjadi hasil penilaian guna membantu manajer mengambil keputusan. Oleh karenanya sistem pendukung keputusan tersebut haruslah sederhana, cepat, mudah dikontrol dan adaptif lengkap dengan isu-isu penting [10].

Sistem pendukung keputusan sebagai alat bantu rekomendasi pemilihan kandidat pejabat struktural ini merupakan sistem yang akan digunakan oleh Kepala Bidang Perencanaan dan Pengembangan Badan Kepegawaian Daerah Pemerintah Kota Tarakan untuk memberikan rekomendasi kepada Tim Baperjakat dalam pemilihan kandidat pejabat struktural di lingkungan Pemerintah Kota Tarakan. Sistem ini menggunakan metode profile matching untuk memberikan rekomendasi kandidat terpilih pada proses pemilihan pejabat struktural. Sistem pendukung keputusan yang dibangun diharapkan mampu mengolah data penilaian kandidat, data kebutuhan kriteria jabatan dan data kriteria yang digunakan dalam penilaian pejabat struktural sehingga mampu memberikan hasil pengurutan alternatif kandidat yang dapat dipertimbangkan untuk direkomendasikan sesuai dengan jabatan yang dibutuhkan.

\subsubsection{Analisis struktur sistem}

Sistem pendukung keputusan sebagai alat bantu rekomendasi pemilihan kandidat pejabat struktural dibangun atas tiga bagian sistem, yaitu input (masukan), proses, dan output (keluaran). Struktur sistem pendukung keputusan tersebut ditunjukkan oleh Gambar 1.

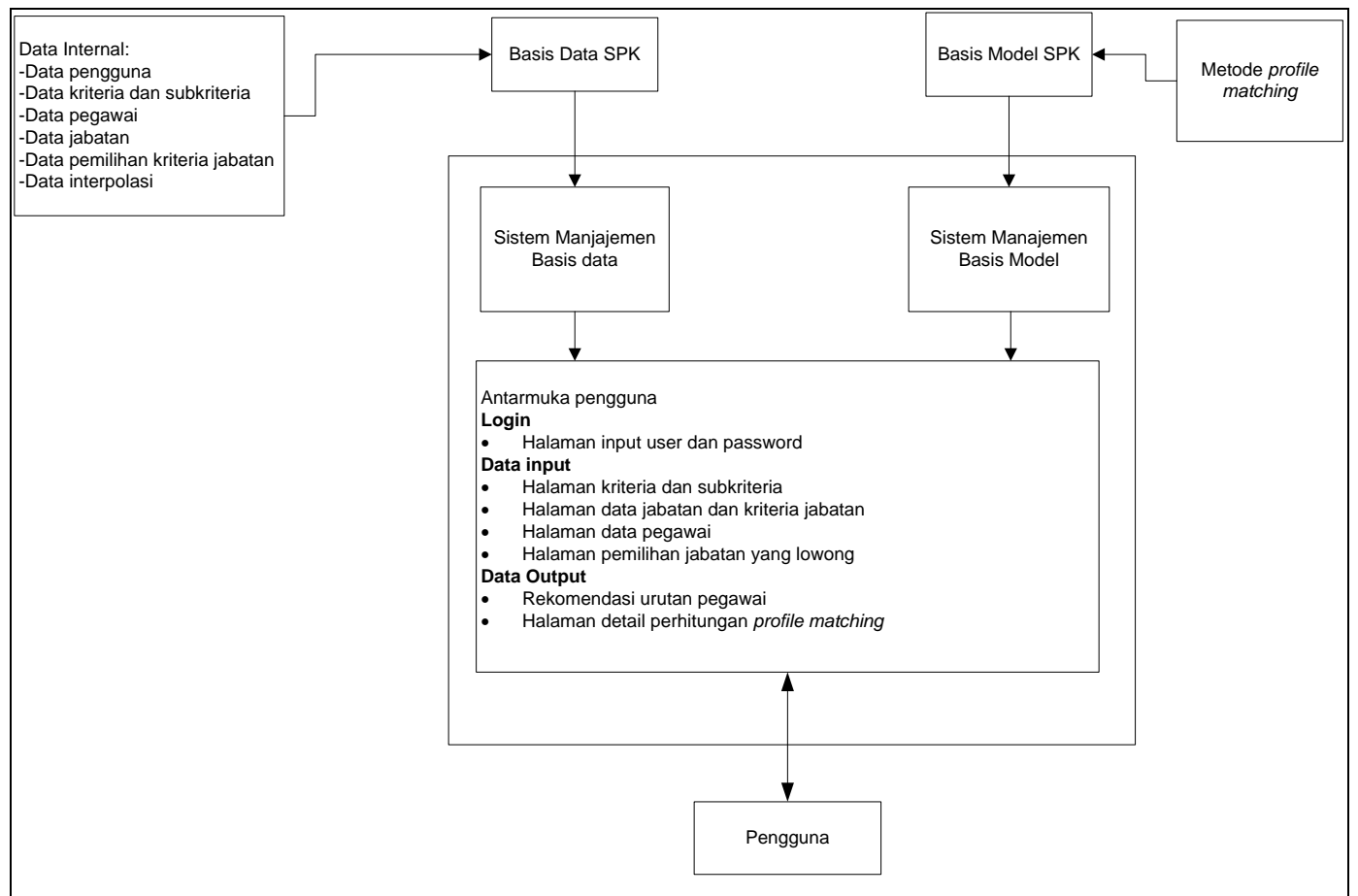

Gambar 1 Struktur sistem pendukung keputusan pemilihan kandidat pejabat struktural menggunakan metode profile mtching 


\subsection{Proses Perancangan Model Keputusan}

Sistem pendukung keputusan rekomendasi pejabat struktural ditentukan dalam beberapa tahapan yaitu:

1. Decision maker menentukan input kriteria jabatan yang lowong. Kemudian memilih daftar kandidat yang akan dilakukan proses perhitungan profile matching. Pengguna sistem ini ialah Kepala Bidang Perencanaan dan Pengembangan Pegawai (Kabid Rembang).

2. Menentukan nilai parameter untuk tiap subkriteria. Di sisi lain, penilaian data pegawai juga harus mengacu pada kebutuhan sistem.

3. Proses yang dilalui oleh pengambil keputusan ialah proses perhitungan profile matching dengan selisih gap antara profil kandidat dan profil target (dalam hal ini jabatan yang lowong), menghitung nilai bobot gap dengan menggunakan metode interpolasi linear kemudian menghitung nilai total.

4. Proses selanjutnya pengurutan rekomendasi kandidat pejabat struktural berdasarkan hasil perhitungan dan disesuaikan dengan kebijakan yang berlaku.

Berdasarkan tahapan yang telah disebutkan, model sistem pendukung keputusan rekomendasi kandidat pejabat struktural di Lingkungkan Pemerintah Kota Tarakan menggunakan profile matching digambarkan melalui flowchart yang terdapat pada Gambar 2.

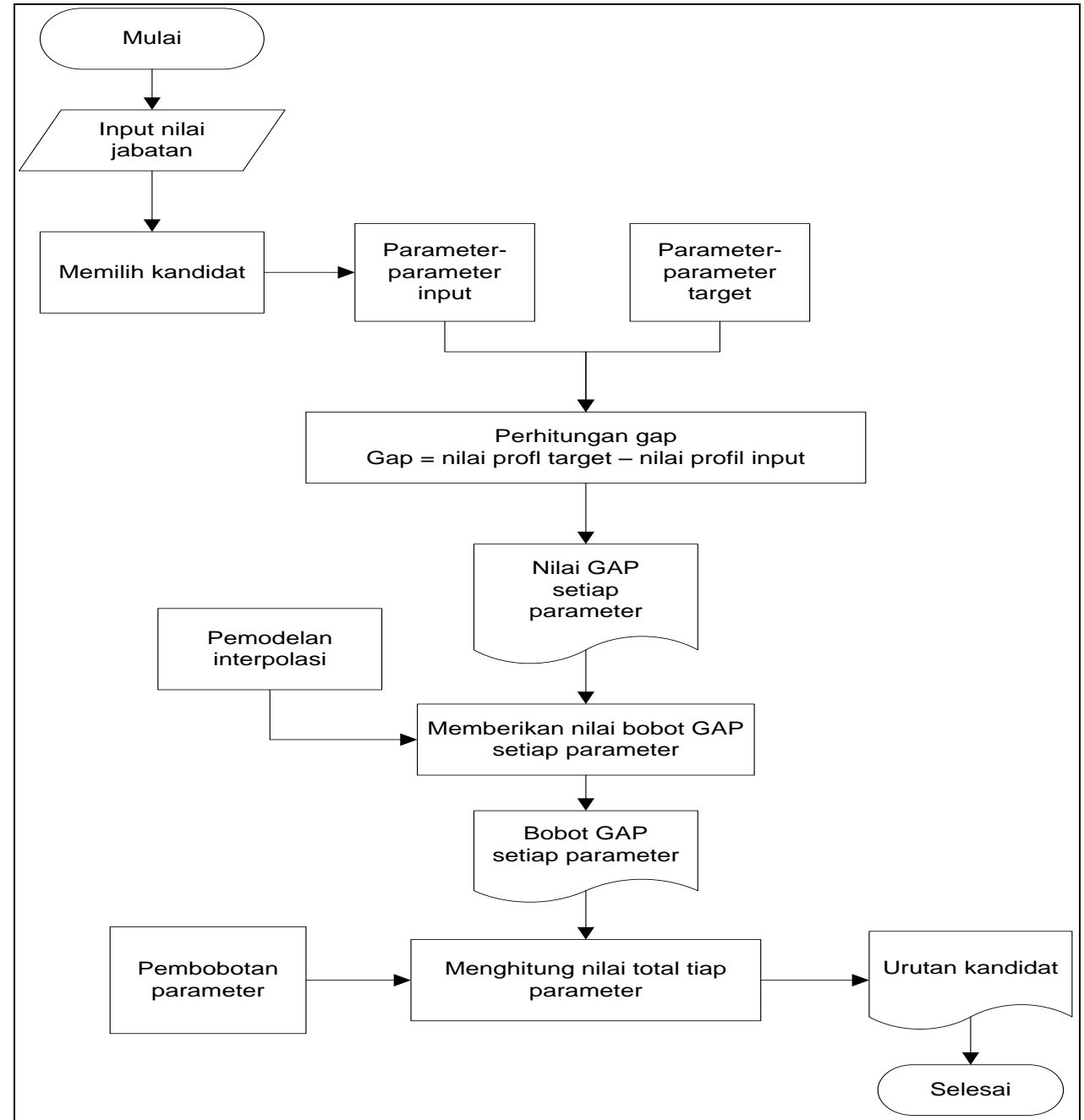

Gambar 2 Flowchart sistem pendukung keputusan dengan metode profile matching 


\subsubsection{Pemodelan Interpolasi Linear}

Pemodelan interpolasi linear dilakukan untuk menghitung nilai bobot gap. Apabila data yang didapat pada kriteria merupakan data numerik, maka perhitungan gap dilakukan dengan cara menghitung selisih antara profil target dengan profil kandidat. Namun apabila data yang didapat berupa data non numerik, maka digunakan rating untuk menentukan nilai gap. Kemudian nilai gap yang dihasilkan akan digunakan untuk proses pemberian nilai bobot gap setiap parameter dengan menggunakan metode interpolasi linear. Hal ini dilakukan agar nilai pemberian bobot lebih akurat dibandingkan dengan menggunakan rating.

\subsubsection{Pemodelan Kriteria Profile Matching}

Proses pemilihan kandidat pejabat struktural memerlukan penilaian dari tim Baperjakat, akan tetapi daftar kandidat real time tidak bisa diberikan pada penilaian ini dikarenakan alasan kerahasiaan data. Hasil akhir dari metode profile matching yaitu mendapatkan profil kandidat yang paling ideal terhadap kebutuhan jabatan yang lowong dan sesuai dengan kebijakan yang berlaku. Tahapan-tahapan yang harus dilakukan pada penelitian ini dalam pemodelan profile matching yaitu:

Tahapan proses pemetaan gap

Tahapan ini merupakan proses membandingkan antara profil kandidat dengan profil jabatan yang lowong dengan menghasilkan selisih nilai yang disebut nilai gap, semakin kecil selisih nilai gap yang didapatkan maka nilai kandidat dengan nilai jabatan yang lowong semakin mendekati/ ideal.

Tahapan penentuan nilai kriteria

Daftar urutan rekomendasi kandidat yang akan diproses pada sistem memiliki penilaian subkriteria yang sama yang mengacu pada kebutuhan sistem. Melalui nilai subkriteria dilakukan pencocokan antara profil kandidat dan profil target berdasarkan skor nilai yang telah ditetapkan. Pada penelitian ini porsi bobot kriteria sudah ditentukan oleh pengambil keputusan berdasarkan presentase bobot. Rincian bobot kriteria dapat dilihat pada Tabel 1.

Tabel 1 Bobot Kriteria

\begin{tabular}{|l|c|}
\hline \multicolumn{1}{|c|}{ Nama Kriteria } & Bobot Kriteria \\
\hline Kepangkatan & $30 \%$ \\
\hline Diklatpim & $10 \%$ \\
\hline Pendidikan Formal & $20 \%$ \\
\hline Riwayat Jabatan & $20 \%$ \\
\hline Diklat & $10 \%$ \\
\hline Disiplin & $10 \%$ \\
\hline
\end{tabular}

Tahapan penentuan rangking

Hasil akhir dari proses profile matching adalah rangking dari kandidat. Penentuan rangking mengacu pada hasil perhitungan kriteria. Apabila terdapat nilai akhir yang sama pada kandidat terpilih maka pengurutan didasarkan pada peraturan perundangan yang berlaku, yakni dengan mengurutkan kandidat yang lebih senior pada urutan teratas.

\subsection{Implementasi Proses Pengolahan Data}

Implementasi proses pengolahan data pada sistem ini terdiri dari beberapa halaman yakni, halaman login, halaman kriteria, halaman subkriteria, halaman data pegawai. Berikut implementasi untuk setiap proses pembuatan sistem. 


\subsubsection{Halaman login}

Proses login ini digunakan untuk melakukan akses terhadap sistem, pengguna akan dapat mengoperasikan menu-menu yang ada pada halaman utama sistem sesuai dengan hak aksesnya sebagai admin baperjakat atau staf kepegawaian. Tampilan halaman login ditunjukkan pada Gambar 3.

\begin{tabular}{|l|}
\hline \multicolumn{1}{|c|}{ LOGIN } \\
\hline username \\
\hline password \\
\hline login \\
\hline
\end{tabular}

Gambar 3 Halaman login

Bila pengguna berhasil melakukan proses login, maka pengguna akan masuk ke halaman utama sebagai admin baperjakat atau staf kepegawaian sesuai dengan username dan password yang terdapat dalam database, sehingga menu yang ditampilkan pada halaman utama sesuai dengan hak akses masing-masing pengguna. Gambar 4 halaman utama untuk admin baperjakat dan Gambar 5 halaman utama untuk admin kepegawaian

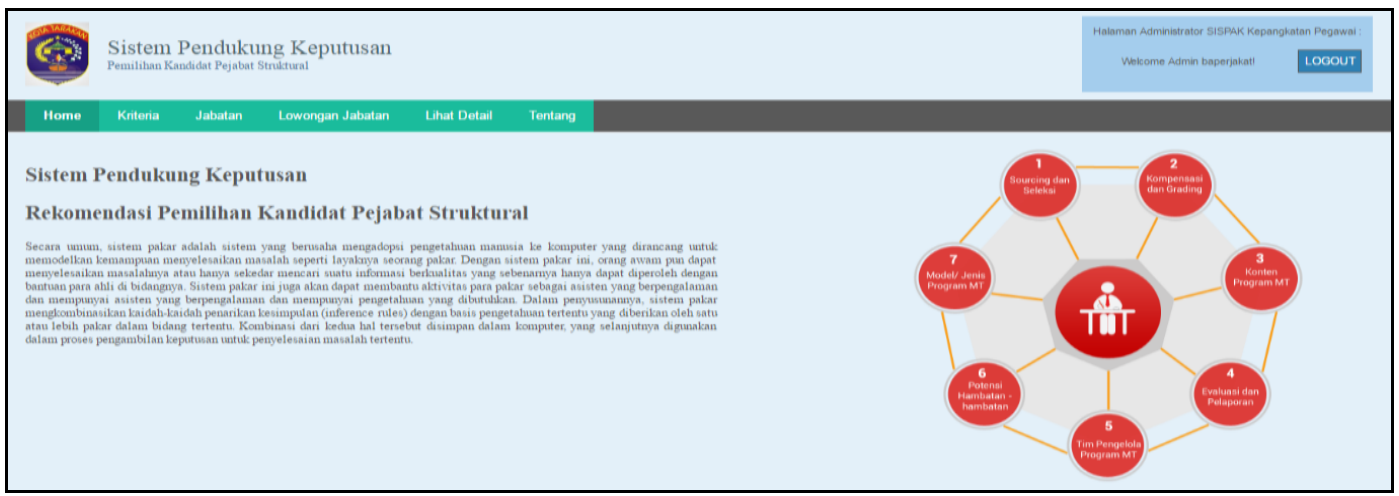

Gambar 4 Halaman utama untuk admin baperjakat

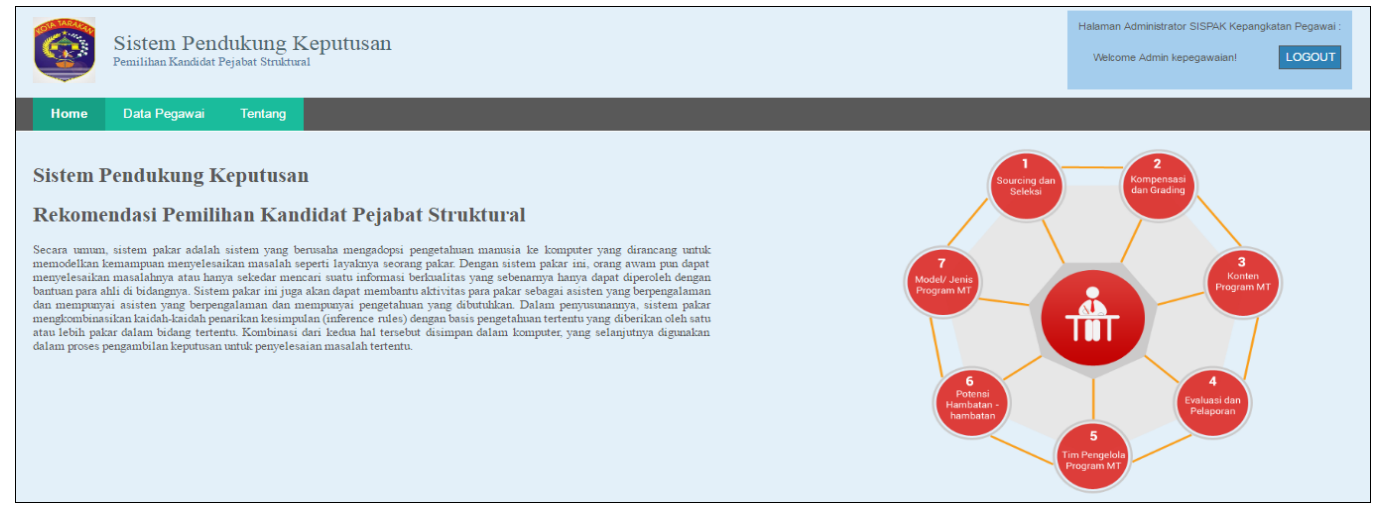

Gambar 0 Halaman utama untuk admin kepegawaian 


\subsubsection{Halaman olah data kriteria}

Menu pengolahan data kriteria digunakan oleh admin baperjakat untuk memasukkan data kriteria ke dalam basis data. Sistem pengolahan ini meliputi proses penyimpanan kriteria baru, proses pengubahan kriteria, dan proses penghapusan kriteria oleh admin baperjakat yang ditunjukkan dalam Gambar 6.

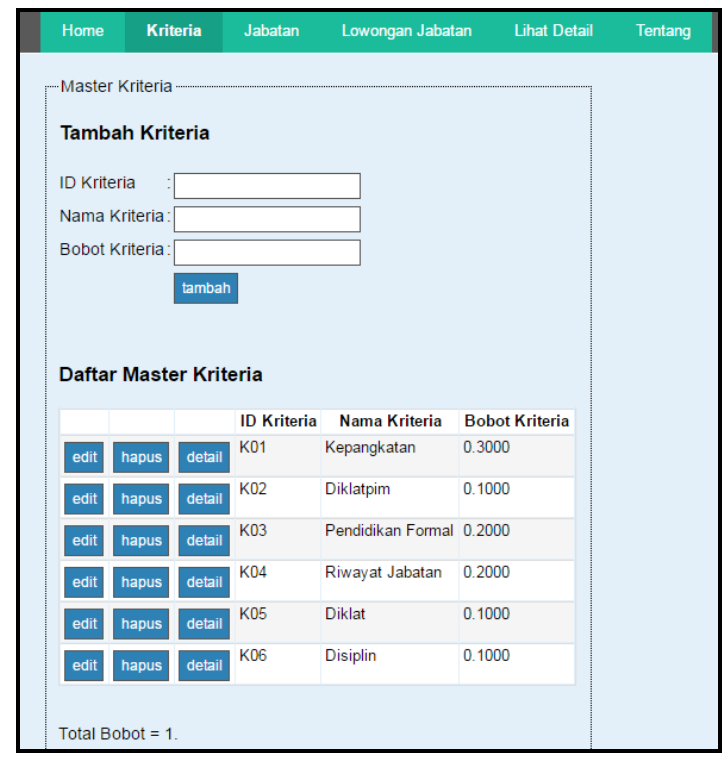

Gambar 6 Halaman olah data kriteria

\subsubsection{Halaman olah data subkriteria}

Pengolahan data subkriteria digunakan untuk memasukkan data subkriteria ke dalam basis data. Sistem pengolahan ini meliputi proses penyimpanan subkriteria baru, proses pengubahan subkriteria, dan proses penghapusan subkriteria yang ditunjukkan pada Gambar 7 .

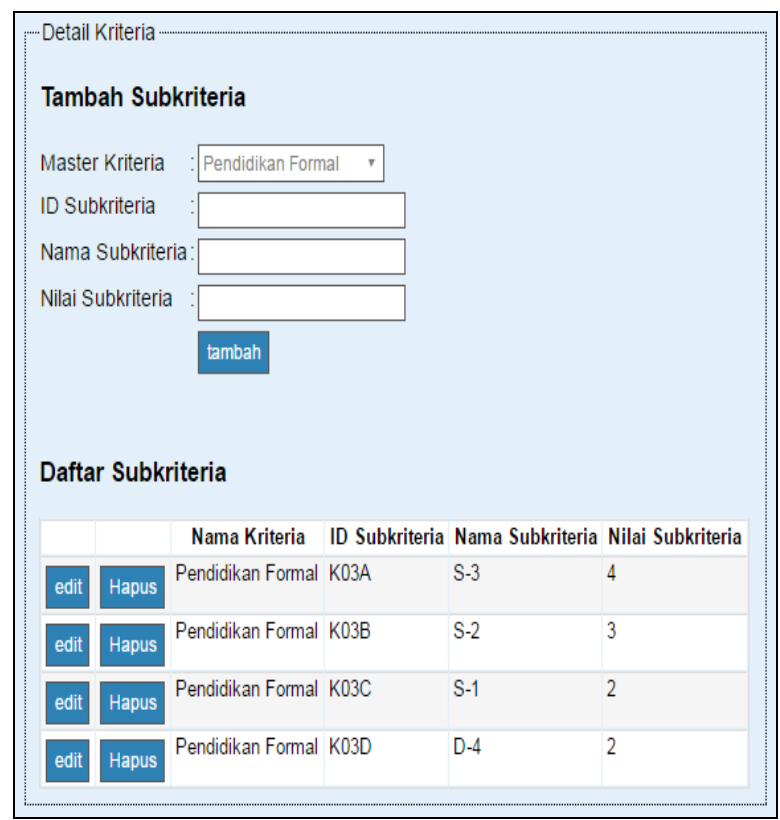

Gambar 7 Halaman olah data subkriteria 


\subsubsection{Halaman olah data jabatan}

Pengolahan data jabatan digunakan untuk memasukkan data jabatan ke dalam basis data. Sistem pengolahan ini meliputi proses penyimpanan, pengubahan dan penghapusan data jabatan yang ditunjukkan pada Gambar 8. Gambar 9 menunjukkan halaman untuk mengisi data kriteria jabatan.

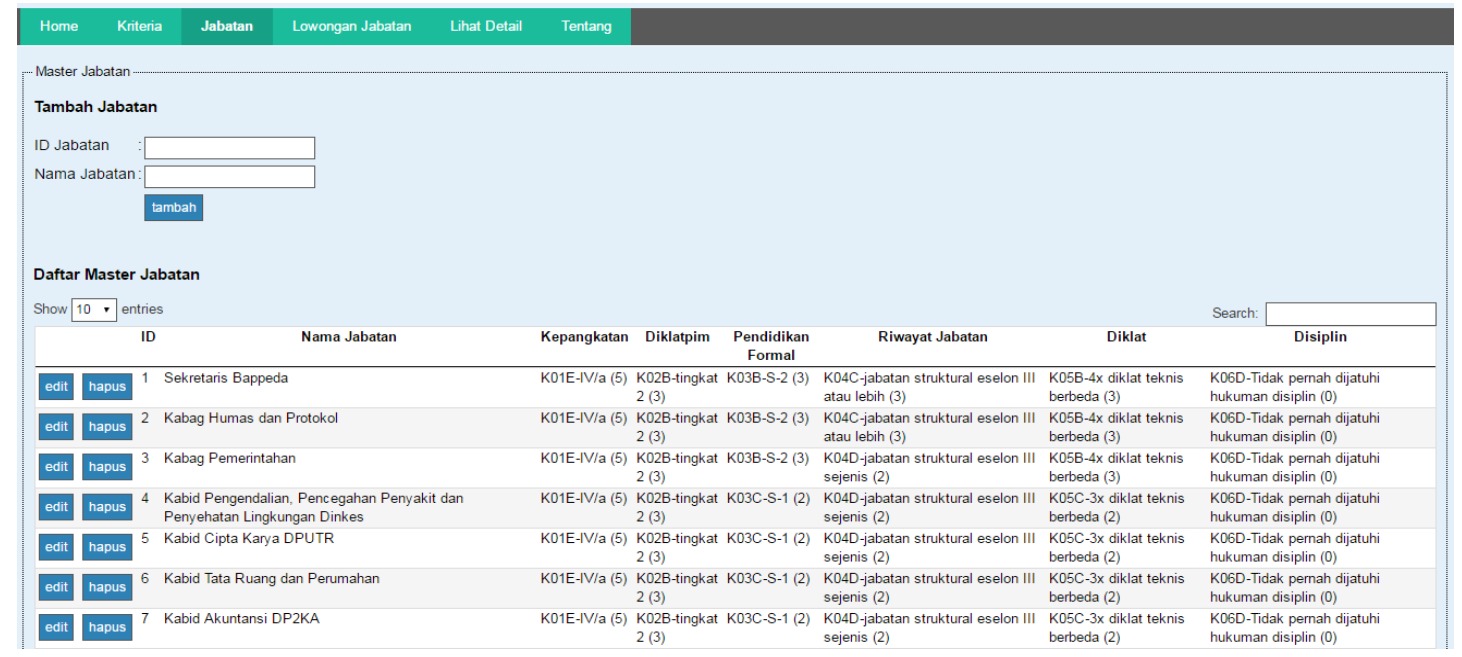

Gambar 8 Halaman olah data jabatan

\begin{tabular}{|c|c|c|c|c|c|c|c|c|}
\hline \multicolumn{9}{|c|}{ Daftar Master Jabatan } \\
\hline & ID & Nama Jabatan & Kepangkatan & Diklatpim & $\begin{array}{l}\text { Pendidikan } \\
\text { Formal }\end{array}$ & Riwayat Jabatan & Diklat & Disiplin \\
\hline \multirow[t]{7}{*}{ save cancel } & 1 & Sekretaris Bappeda & IN/a (5) $\quad$, & tingkat 2 (3) - & \$.2(3) & jabatan struk. & $4 x$ diklat teln . & Tidak pernat - \\
\hline & 2 & Kabag Humas dan Protokol & \begin{tabular}{|l|} 
Piin Target- \\
IVle (9) \\
IVId (8)
\end{tabular} & $\begin{array}{l}\text { Ko2B-tingkat2 } \\
\text { (3) }\end{array}$ & K03B-S-2 (3) & $\begin{array}{l}\text { K04C-jabatan struktural eselon III } \\
\text { atau lebih (3) }\end{array}$ & $\begin{array}{l}\text { K05B-4x diklat teknis } \\
\text { berbeda (3) }\end{array}$ & $\begin{array}{l}\text { K06D-Tidak pernah dijatuhi hukuman } \\
\text { disiplin (0) }\end{array}$ \\
\hline & 3 & Kabag Pemerintahan & $\begin{array}{l}\mid N / c(7) \\
I / b(6)\end{array}$ & $\begin{array}{l}\text { K02B-tingkat 2 } \\
\text { (3) }\end{array}$ & K03B-S-2 (3) & $\begin{array}{l}\text { K04D-jabatan struktural eselon III } \\
\text { sejenis (2) }\end{array}$ & $\begin{array}{l}\text { K05B-4x diklat teknis } \\
\text { berbeda (3) }\end{array}$ & $\begin{array}{l}\text { K06D-Tidak pernah dijatuhi hukuman } \\
\text { disiplin (0) }\end{array}$ \\
\hline & 4 & $\begin{array}{l}\text { Kabid Pengendalian, Pencegahan Penyakit dan Penyehatan } \\
\text { Lingkungan Dinkes }\end{array}$ & 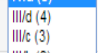 & $\begin{array}{l}\text { K02B-tingkat } 2 \\
\text { (3) }\end{array}$ & K03C-S-1 (2) & $\begin{array}{l}\text { K04D-jabatan struktural eselon III } \\
\text { sejenis (2) }\end{array}$ & $\begin{array}{l}\text { K05C-3x diklat teknis } \\
\text { berbeda (2) }\end{array}$ & $\begin{array}{l}\text { K06D-Tidak pernah dijatuhi hukuman } \\
\text { disiplin (0) }\end{array}$ \\
\hline & 5 & Kabid Cipta Karya DPUTR & IIII/b (2) & $\begin{array}{l}\text { Ko2B-tingkat2 } \\
\text { (3) }\end{array}$ & K03C-S-1 (2) & $\begin{array}{l}\text { K04D-jabatan struktural eselon III } \\
\text { sejenis (2) }\end{array}$ & $\begin{array}{l}\text { K05C-3x diklat teknis } \\
\text { berbeda (2) }\end{array}$ & $\begin{array}{l}\text { Ko6D-Tidak pernah dijatuhi hukuman } \\
\text { disiplin (0) }\end{array}$ \\
\hline & 6 & Kabid Tata Ruang dan Perumahan & K01E-N/a (5) & $\begin{array}{l}\text { K02B-tingkat 2 } \\
\text { (3) }\end{array}$ & K03C-S-1 (2) & $\begin{array}{l}\text { K04D-jabatan struktural eselon III } \\
\text { sejenis (2) }\end{array}$ & $\begin{array}{l}\text { K05C-3x diklat teknis } \\
\text { berbeda (2) }\end{array}$ & $\begin{array}{l}\text { K06D-Tidak pernah dijatuhi hukuman } \\
\text { disiplin (0) }\end{array}$ \\
\hline & 7 & Kabid Akuntansi DP2KA & K01E-N/a (5) & $\begin{array}{l}\text { K02B-tingkat 2 } \\
\text { (3) }\end{array}$ & KO3C-S-1 (2) & $\begin{array}{l}\text { K04D-jabatan struktural eselon III } \\
\text { sejenis (2) }\end{array}$ & $\begin{array}{l}\text { K05C-3x diklat teknis } \\
\text { berbeda (2) }\end{array}$ & $\begin{array}{l}\text { K06D-Tidak pernah dijatuhi hukuman } \\
\text { disiplin (0) }\end{array}$ \\
\hline
\end{tabular}

Gambar 9 Halaman pengisian kriteria jabatan

\subsubsection{Halaman olah data pegawai}

Menu pengolahan data pegawai digunakan oleh staf kepegawaian untuk memasukkan informasi data kepegawaian yang dibutuhkan oleh sistem. Sistem pengolahan ini meliputi proses penyimpanan, pengubahan dan penghapusan data oleh staf kepegawaian. Halaman data pegawai ditunjukkan pada Gambar 10. 


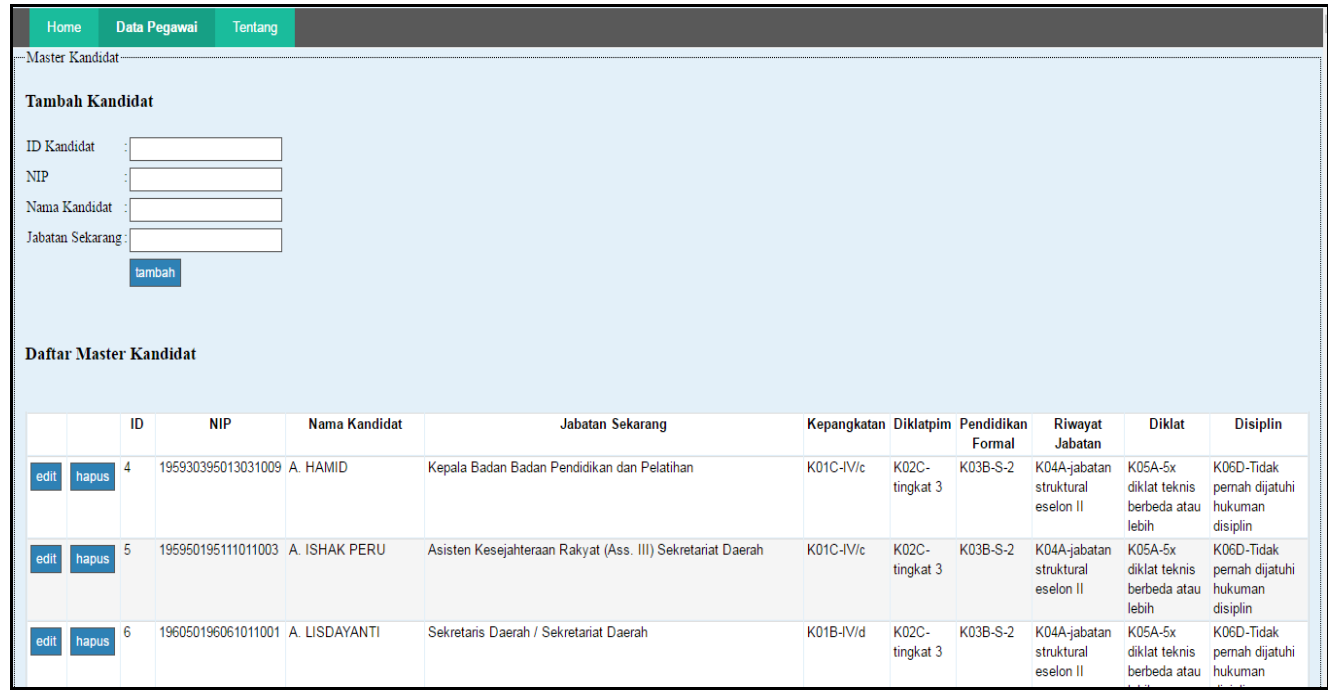

Gambar 10 Halaman olah data pegawai

\section{HASIL DAN PEMBAHASAN}

\subsection{Pengujian kesesuaian pegawai pada jabatan struktural}

Penempatan pegawai pada jabatan struktural yang sesuai ditentukan dengan menggunakan metode profile matching. Untuk pengujian kesesuaian pegawai pada jabatan struktural digunakan 5 jabatan yang dapat merepresentasikan eselon IIIa, eselon IIIb, eselon IVa, eselon IVb, eselon Va. Tabel 2 menunjukkan jabatan yang dipilih untuk dilakukan pengujian terhadap sistem dan Tabel 3 menunjukkan kebutuhan kriteria jabatan yang sudah dipetakan sesuai rancangan sistem.

Pengujian dilakukan pada 3 kondisi, yaitu:

1. Menggunakan data penilaian kandidat dengan hasil rekomendasi terbaik sesuai kebutuhan kriteria jabatan.

2. Menggunakan data penilaian kandidat dengan 3 kriteria yang mirip dengan kebutuhan jabatan.

3. Menggunakan data penilaian kriteria yang sangat tidak mirip dengan kebutuhan jabatan.

Tabel 2 Daftar jabatan yang dipilih untuk pengujian terhadap sistem

\begin{tabular}{|c|c|c|c|c|c|c|c|c|}
\hline \multirow[t]{2}{*}{ ID } & \multirow{2}{*}{ Jabatan } & \multirow{2}{*}{ Eselon } & Kepangkatan & Diklatpim & \begin{tabular}{|c|} 
Pendidikan \\
Formal
\end{tabular} & $\begin{array}{l}\text { Riwayat } \\
\text { Jabatan }\end{array}$ & Diklat & Disiplin \\
\hline & & & $30 \%$ & $10 \%$ & $20 \%$ & $20 \%$ & $10 \%$ & $10 \%$ \\
\hline 1 & $\begin{array}{l}\text { Sekretaris } \\
\text { Bappeda }\end{array}$ & III a & IV/a & Tingkat 2 & S2 & $\begin{array}{r}\text { Jabatan } \\
\text { struktural } \\
\text { eselon III } \\
\text { atau lebih } \\
\end{array}$ & $\begin{array}{r}4 x \\
\text { diklat } \\
\text { berbeda }\end{array}$ & $\begin{array}{r}\text { Tidak pernah } \\
\text { dijatuhi hukuman } \\
\text { disiplin }\end{array}$ \\
\hline 6 & $\begin{array}{l}\text { Kabid Tata } \\
\text { Ruang dan } \\
\text { Perumahan }\end{array}$ & III b & IV/a & Tingkat 2 & S1/D4 & $\begin{array}{r}\text { Jabatan } \\
\text { struktural } \\
\text { eselon III } \\
\text { sejenis } \\
\end{array}$ & $\begin{array}{r}3 x \\
\text { diklat } \\
\text { berbeda }\end{array}$ & $\begin{array}{r}\text { Tidak pernah } \\
\text { dijatuhi hukuman } \\
\text { disiplin }\end{array}$ \\
\hline 10 & $\begin{array}{l}\text { Lurah } \\
\text { Mamburungan } \\
\text { Timur }\end{array}$ & IV a & $\mathrm{III} / \mathrm{d}$ & Tingkat 3 & S1/D4 & - & $\begin{array}{r}2 \mathrm{x} \\
\text { diklat } \\
\text { berbeda }\end{array}$ & $\begin{array}{r}\text { Tidak pernah } \\
\text { dijatuhi hukuman } \\
\text { disiplin }\end{array}$ \\
\hline 38 & $\begin{array}{l}\text { Sekretaris } \\
\text { Kelurahan } \\
\text { Gunung Lingkas }\end{array}$ & IV b & $\mathrm{III} / \mathrm{c}$ & Tingkat 3 & S1/D4 & - & $\begin{array}{r}2 \mathrm{x} \\
\text { diklat } \\
\text { berbeda }\end{array}$ & $\begin{array}{r}\text { Tidak pernah } \\
\text { dijatuhi hukuman } \\
\text { disiplin }\end{array}$ \\
\hline 31 & $\begin{array}{l}\text { Kasubbag Tata } \\
\text { Usaha SMPN } 9 \\
\text { Dinas Pendidikan }\end{array}$ & $\mathrm{V} \mathrm{a}$ & $\mathrm{III} / \mathrm{b}$ & Tingkat 2 & S1/D4 & - & $\begin{array}{r}2 \mathrm{x} \\
\text { diklat } \\
\text { berbeda }\end{array}$ & $\begin{array}{r}\text { Tidak pernah } \\
\text { dijatuhi hukuman } \\
\text { disiplin }\end{array}$ \\
\hline
\end{tabular}


Tabel 3 Nilai kriteria jabatan

\begin{tabular}{|c|c|c|c|c|c|c|c|c|}
\hline \multirow[t]{2}{*}{ ID } & \multirow[t]{2}{*}{ Jabatan } & \multirow[t]{2}{*}{ Eselon } & Kepangkatan & Diklatpim & $\begin{array}{l}\text { Pendidikan } \\
\text { Formal } \\
\end{array}$ & $\begin{array}{l}\text { Riwayat } \\
\text { Jabatan }\end{array}$ & Diklat & Disiplin \\
\hline & & & $30 \%$ & $10 \%$ & $\mathbf{2 0 \%}$ & $20 \%$ & $10 \%$ & $10 \%$ \\
\hline 1 & $\begin{array}{l}\text { Sekretaris } \\
\text { Bappeda }\end{array}$ & III a & 5 & 3 & 3 & 3 & 3 & 0 \\
\hline 6 & $\begin{array}{l}\text { Kabid Tata } \\
\text { Ruang dan } \\
\text { Perumahan }\end{array}$ & III b & 5 & 3 & 2 & 2 & 2 & 0 \\
\hline 10 & $\begin{array}{l}\text { Lurah } \\
\text { Mamburungan } \\
\text { Timur }\end{array}$ & IV a & 4 & 2 & 2 & 0 & 1 & 0 \\
\hline 38 & $\begin{array}{l}\text { Sekretaris } \\
\text { Kelurahan } \\
\text { Gunung } \\
\text { Lingkas }\end{array}$ & IV b & 3 & 2 & 2 & 0 & 1 & 0 \\
\hline 31 & $\begin{array}{l}\text { Kasubbag Tata } \\
\text { Usaha SMPN } \\
9 \text { Dinas } \\
\text { Pendidikan }\end{array}$ & $\mathrm{V} \mathrm{a}$ & 2 & 2 & 2 & 0 & 1 & 0 \\
\hline
\end{tabular}

Pengujian 1 menggunakan data penilaian kandidat dengan hasil rekomendasi terbaik dilakukan terhadap 5 jabatan dengan masing-masing jabatan memiliki daftar nama kandidat yang paling mendekati dengan kebutuhan kriteria jabatan yang tersedia. Salah satu contoh pada hasil pengujian 1 ialah pada data pengujian eselon IIIa dengan nama jabatan Sekretaris Bappeda. Urutan yang direkomendasikan ialah urutan yang sesuai daftar kandidat yang dipilih. Jika terdapat lebih dari 1 kandidat yang memiliki nilai akhir yang sama, maka daftar kandidat diurutkan berdasarkan urutan usia. Hal ini diakomodasikan dengan melihat daftar Nomor Induk Pegawai (NIP). Dari pengujian yang dilakukan terhadap 7 kandidat, diketahui 5 kandidat memiliki nilai yang paling ideal dengan jabatan tersebut dengan nilai total akhir 3, 1 kandidat dengan nilai akhir 2.85 dan 1 kandidat dengan nilai akhir 2.7.

Pengujian 2 menggunakan data penilaian kandidat dengan 3 kriteria yang mirip dengan kebutuhan jabatan. Pada pengujian ini, data kandidat yang dipilih ialah yang memiliki kriteria 'Kepangkatan', 'Jumlah Diklat' dan 'Kedisiplinan' yang ideal dengan kebutuhan jabatan, sedangkan untuk kriteria lainnya dipilih kandidat yang tidak memiliki nilai yang sama dengan kebutuhan jabatan. Salah satu contoh pada hasil pengujian 2 ialah pada data pengujian eselon IIIa dengan nama jabatan Sekretaris Bappeda. Dari pengujian yang dilakukan terhadap tujuh kandidat, diketahui satu kandidat dengan nilai 2.7, tiga kandidat dengan nilai akhir 2.4, satu kandidat dengan nilai akhir 2.25 dan dua kandidat dengan nilai akhir 2.1.

Pengujian 3 menggunakan data penilaian kriteria pada kandidat sangat tidak mirip dengan kebutuhan jabatan. Pada pengujian ini, data kandidat yang dipilih ialah yang berbeda dengan kebutuhan kriteria jabatan. Salah satu contoh pada hasil pengujian 3 ialah pada data pengujian eselon IIIa dengan nama jabatan Sekretaris Bappeda. Dari pengujian yang dilakukan terhadap tujuh kandidat, diketahui satu kandidat dengan nilai akhir 1.9, satu kandidat dengan nilai akhir 1.55, satu kandidat dengan nilai akhir 1.4, satu kandidat dengan nilai akhir 0.3, dua kandidat dengan nilai akhir 0.15 dan satu kandidat dengan nilai akhir 0 .

Berdasarkan ketiga hasil pengujian maka kandidat yang memiliki kriteria ideal juga memiliki nilai yang lebih tinggi dibandingkan dengan kandidat yang hanya memiliki beberapa nilai kriteria yang sama dan memiki nilai kriteria yang jauh berbeda dengan kriteria jabatan yang dibutuhkan. Nilai kandidat yang semakin mendekati dengan kebutuhan kriteria jabatan maka semakin tinggi nilai yang dihasilkan sistem dan sebaliknya. Hal ini dapat memberikan rekomendasi urutan kandidat tepat sesuai dengan kebutuhan kriteria jabatan. 


\section{KESIMPULAN}

Kesimpulan yang diperoleh dari penelitian ini adalah:

1. Sistem pendukung keputusan yang diusulkan dapat menghasilkan urutan rekomendasi kandidat terbaik dalam pemilihan jabatan struktural di lingkungan Pemerintahan Kota Tarakan.

2. Kebutuhan kriteria jabatan yang sesuai dengan penilaian kandidat dapat menghasilkan nilai yang berbeda sesuai dengan hasil perhitungan.

3. Perubahan nilai profil kandidat, dan jumlah subkriteria yang digunakan untuk kriteria jabatan, dapat mempengaruhi kedekatan kandidat dengan jabatan yang tersedia.

4. Penggunaan metodeprofile matching untuk kasus yang mengganggap bahwa nilai tertinggi adalah nilai terbaik mengharuskan nilai ideal yang digunakan adalah nilai maksimum agar tidak terjadi ekspektasi yang melebihi nilai ideal.

5. Dengan memanfaatkan metode profile matching, maka penilaian kandidat dapat dilakukan oleh sistem, sehingga membantu mengatasi masalah yang muncul karena sebelumnya proses ini hanya dilakukan secara manual sehingga sistem ini mampu meminimalisisr terjadinya keputusan yang subjektif.

6. Perubahan bobot kriteria mempengaruhi alternatif keputusan yang dihasilkan.

\section{SARAN}

Berikut beberapa saran yang dapat diberikan terkait dengan penelitian yang telah dilakukan dan pengembangan sistem selanjutnya:

1. Data-data yang dibutuhkan harus dimaukkan ke dalam sistem dengan teliti agar tercapainya tujuan yang diinginkan dari hasil sistem pendukung keputusan sebagai alat bantu rekomendasi pemilihan kandidat pejabat struktural di Lingkungan pemerintah Kota Tarakan.

2. Kriteria yang dimasukkan dapat dikembangkan dan disesuaikan dengan peraturan perundang-undangan yang mungkin bersifat dinamis.

3. Sistem pendukung keputusan selanjutnya dapat diintegrasikan dengan sistem kepegawaian yang ada sehingga diharapkan mampu memanfaatkan teknologi informasi untuk kebutuhan data antar divisi.

4. Penelitian ini dapat dikembangkan dengan memanfaatkan metode keputusan lainnya, yang disesuaikan dengan peraturan perundang-undangan yang berlaku.

\section{DAFTAR PUSTAKA}

[1] Judas, A., 2013, Mutasi dan Promosi Jabatan Pengaruhnya Terhadap Prestasi Kerja Pegawai pada Kanwil Ditjen Kekayaan Negara Suluttenggo dan Maluku Utara di Manado, EMBA, 1, 4, 1219-1228.

[2] Dasplin, 2014, Analisis Pengaruh Mutasi, Dan Promosi Jabatan Terhadap Pengembangan Karir Pegawai Di Manado, Riset Bisnis dan Manajemen, 2, 3, 15-24.

[3] Effendi, A., 2007, Manajemen Pegawai Negeri Sipil yang Efektif, Sumber Daya Manusia, Andi, Yogyakarta.

[4] Kusrini, 2007, Konsep dan Aplikasi Sistem Pendukung Keputusan, Andi, Yogyakarta. 
[5] Turban, E., Aronson, J. dan Liang, P., 2005, Decision Support System and Intelligent Systems, 7th penyunt. Pearson Education Inc., Upper Saddle River, New Jersey.

[6] Handojo, A., Setiabudi, D. dan Yunita, R., 2003, Pembuatan Aplikasi Sistem Pendukung Keputusan untuk Proses Kenaikan Jabatan dan Perencanaan Karis pada PT. X, Jurnal Informatika, 4, 2.

[7] Lu, Q., Eichstaedt, M. dan Ford, D., 1998, Efficient profile matching for large scale Webcasting, Computer Networks and ISDN Systems, Volume 30, 443-455.

[8] Biesalski, E. dan Abecker, A., 2008, Skill-Profile Matching with Similarity Measures, Research Center for Information Technologies, Volume 3, 210-218.

[9] Iqbal, 2011, Sistem Pendukung Keputusan Penentuan Penempatan Bidan PTT (Pegawai Tidak Tetap) pada Kabupaten Bireun, Tesis, Program Pasca Sarjana Ilmu Komputer, Univ. Gadjah Mada, Yogyakarta.

[10] Little, J. D. C., 1970, Models and Managers: The Concept of a Decision Calculus, Management Science, 16, 8. 